\title{
Effects of the proapoptotic regulator Bcl-2/adenovirus EIB 19-kDa-interacting protein 3 on the chemosensitivity of human colon cancer cell lines
}

\author{
ZI WANG $^{1 *}$, CHUNMEI HUANG ${ }^{2 *}$, JIANSHUANG ZENG ${ }^{1}$, QIAN DENG ${ }^{1}$, HUI ZENG $^{1}$, ZHEN LIU $^{1}$, \\ XINGCHEN PENG ${ }^{3}$, FENG BI ${ }^{1,3}$, QIULIN TANG ${ }^{3}$ and ZHIPING LI ${ }^{1}$ \\ ${ }^{1}$ Department of Radiation Oncology, Cancer Center, West China Hospital, Sichuan University, Chengdu, Sichuan 610041; \\ ${ }^{2}$ Department of Oncology, Meishan People's Hospital, Meishan, Sichuan 620010; \\ ${ }^{3}$ Laboratory of Signal Transduction and Molecular Targeting Therapy, State Key Laboratory of Biotherapy/Department of \\ Medical Oncology, West China Hospital, Sichuan University, Chengdu, Sichuan 610041, P.R. China
}

Received May 29, 2012; Accepted August 29, 2012

DOI: $10.3892 / \mathrm{ol} .2012 .933$

\begin{abstract}
In the clinical setting, drug resistance remains a significant obstacle for successful chemotherapy. Bcl-2/adenovirus EIB 19-kDa-interacting protein 3 (BNIP3) is a proapoptotic member of the Bcl-2 family. To address its potential as a therapeutic target for chemosensitisation, this study investigated the effect of BNIP3 expression on chemosensitivity and reversal of oxaliplatin (L-OHP) resistance in human colon cancer cell lines. A plasmid expressing the BNIP3 gene was transfected into human parental colon cancer cell lines (SW620 and colo320) and L-OHP-resistant colon cancer cell lines (SW620/L-OHP and colo320/L-OHP) using Lipofectamine $^{\mathrm{TM}} 2000$, and the transfection efficiency was determined using fluorescence optics. Western blot analysis identified that SW620/L-OHP and colo320/L-OHP cells expressed lower levels of BNIP3 protein compared with the SW620 and colo320 cells. Transfection with the recombinant $B N I P 3$ plasmid revealed an increase in BNIP3 expression in tumour cells. Following transfection with pDsRed-BNIP3, the chemosensitivity of parental and L-OHP-resistant cell lines to L-OHP was increased $(\mathrm{P}<0.01)$, as detected by the Cell Counting Kit-8 (CCK8) assay. Hoechst 33342 staining and flow cytometry revealed that the effects on L-OHP-induced apoptosis were enhanced by the overexpression of BNIP3. Chemosensitisation in human colon cancer cells was observed following treatment with the recombinant BNIP3 plasmid
\end{abstract}

Correspondence to: Dr Zhiping Li, Department of Radiation Oncology, Cancer Center, West China Hospital, Sichuan University, 37 Guoxue Road, Chengdu, Sichuan 610041, P.R. China

E-mail: lizhiping620312@yahoo.com.cn

*Contributed equally

Key words: Bcl-2/adenovirus EIB 19-kDa-interacting protein 3, colon cancer, drug resistance, oxaliplatin, chemosensitisation in vitro. The results of this study suggest that BNIP3 is a potential therapeutic target for reversing the resistance of L-OHP-resistant colon cancer cells to L-OHP.

\section{Introduction}

Colon cancer, one of the most common types of malignant tumours worldwide (1), is primarily treated using a chemotherapeutic approach (2). Recently, oxaliplatin (L-OHP) has been employed as an agent for colon cancer chemotherapy (3); however, drug resistance has posed problems in the success of this treatment (4). Thus, it is of value and interest to identify genes that influence chemosensitivity to specific drugs.

The proapoptotic protein $\mathrm{Bcl}-2$ /adenovirus EIB 19-kDa-interacting protein 3 (BNIP3), a member of the Bcl-2 family of proteins, has been a research topic of interest in recent years. BNIP3 is a mitochondrial protein that interacts with the E1B 19-kDa adenovirus protein and Bcl-2 (5), and its expression is reduced in the majority of tumours, including pancreatic, haematopoietic and gastric cancers (6-8). Tumour chemoresistance correlates with the abnormal expression of BNIP3, and our previous study has demonstrated that BNIP3 may play a role in the enhancement of radiotherapy efficiency (9). Previous studies have revealed that the downregulation of BNIP3 in pancreatic cancer cells increased the resistance to 5-fluorouracil (5-FU) and gemcitabine $(10,11)$. It has been suggested that the loss of BNIP3 expression, which occurs late in pancreatic cancer, contributes to chemotherapy resistance and correlates with poor prognoses $(10,11)$. Murai et al (7) identified that the expression of BNIP3 decreased in colon cancer cell lines that were chemoresistant to 5-FU. Tang et al (12) also demonstrated that colon cancer cell lines resistant to L-OHP expressed low levels of BNIP3, and were resistant to 5-FU. Other studies have reached similar conclusions, indicating that BNIP3 expression correlates with chemoresistance $(11,13,14)$. Whether the overexpression of BNIP3 correlates with the reversal of drug resistance in tumour cells remains unknown. Therefore, this study investigated the effect of BNIP3 overexpression on 
the chemosensitivity of parental and L-OHP-resistant colon cancer cell lines.

\section{Materials and methods}

Cell culture. The human parental colon cancer cell lines (SW620 and colo320) and L-OHP-resistant colon cancer cell lines (SW620/L-OHP and colo320/L-OHP) were a gift from the Laboratory of Signal Transduction and Molecular Targeting Therapy of West China Hospital (Sichuan University, China). SW620 and SW620/L-OHP cells were cultured in RPMI-1640 medium supplemented with $10 \%$ foetal calf serum and maintained in an atmosphere of 5\% $\mathrm{CO}_{2}$ at $37^{\circ} \mathrm{C}$. Colo320 and colo320/L-OHP cells were also cultured in RPMI-1640 medium supplemented with $10 \%$ foetal calf serum, but maintained in an atmosphere under $5 \%$ $\mathrm{CO}_{2}$ at $37^{\circ} \mathrm{C}$.

Transient transfection. Plasmids, pDsRed-N1 and pDsRed-BNIP3, were acquired from Dr Chen Ni (Department of Pathology, West China Hospital) and were sequenced by Invitrogen Life Technologies (Carlsbad, CA, USA). We extracted and purified plasmid DNA from Escherichia coli cell lysates using a PureLink ${ }^{\mathrm{TM}}$ HiPure Plasmid DNA purification kit (Invitrogen Life Technologies). The four colon cancer cell lines (SW620, SW620/L-OHP, colo320 and colo320/L-OHP) were transfected with pDsRed-N1 or pDsRed-BNIP3 using Lipofectamine $^{\mathrm{TM}} 2000$ (Invitrogen Life Technologies). Cells were briefly trypsinised and plated onto 6-well plates. The transfection reagent was then added and incubated at room temperature for $5 \mathrm{~min}$. The appropriate volume of plasmid DNA was added and the cells were incubated for an additional $20 \mathrm{~min}$. Fluorescein-labelled pDsRed-N1- or pDsRed-BNIP3-transfected cells were examined under fluorescence optics to determine transfection efficiency after $24 \mathrm{~h}$. Cells were then prepared for western blot analysis, cytotoxicity assays, flow cytometry or Hoechst 33342 staining.

Western blot analysis. Total protein was extracted using a lysis buffer containing $50 \mathrm{mM}$ Tris- $\mathrm{HCl}, 150 \mathrm{mM} \mathrm{NaCl}, 1 \%$ Triton $\mathrm{X}-100,0.1 \%$ sodium dodecyl sulfate (SDS), $1 \mathrm{mM}$ phenylmethylsulphonyl fluoride (PMSF), $0.5 \mathrm{mM}$ EDTA, $0.61 \mathrm{mM}$ leupeptin and $0.1 \%$ pepstatin. Equal amounts of protein were separated by SDS-PAGE and electrophoretically transferred onto nitrocellulose membranes. The membranes were blocked with 5\% non-fat milk in TBST and incubated with BNIP3 and $\beta$-actin antibodies (Sigma-Aldrich, St. Louis, MO, USA) overnight at $4^{\circ} \mathrm{C}$. Once the membranes were exposed to the respective secondary antibody for $2 \mathrm{~h}$, they were analysed by chemiluminescence detection and autoradiography (Odyssey Imaging System; LI-COR Biosciences, Lincoln, NE, USA).

Groups. A total of 6 groups were analysed in this study: control [normal saline (NS)], pDsRed-N1, pDsRed-BNIP3, L-OHP, pDsRed-N1 + L-OHP and pDsRed-BNIP3 + L-OHP.

Cytotoxicity assays. Cells were seeded into 96-well plates at a density of $1 \times 10^{3}$ cells/well in $100 \mu 1$ culture medium and allowed to adhere overnight. The cells were transfected with control (NS) or plasmid DNA (pDsRed-N1 or pDsRed-BNIP3), and after $48 \mathrm{~h}$ the cells were exposed to increasing concentrations (0.01-20 $\mu \mathrm{g} / \mathrm{ml})$ of L-OHP (Sanofi Aventis Co., Paris, France) for $24 \mathrm{~h}$. The cells were incubated in L-OHP-free medium for $48 \mathrm{~h}$, and then in 9\% Cell Counting Kit-8 (CCK8; 1:10; Dojindo Laboratories Co., Ltd., Kumamoto, Japan) for $4 \mathrm{~h}$ at $37^{\circ} \mathrm{C}$. Once the absorbance at $450 \mathrm{~nm}$ was recorded, the inhibitory concentration of $50 \%$ of cells (IC50) was calculated, and the resistance index (RI) and reversal resistance ratio were determined using the following equations: RI = IC50 of drug resistant cell line/IC50 of parent cell line; reversal resistance ratio $=$ IC50 of cells before reversal/IC50 of cells after reversal. The assays were conducted in triplicate and repeated at least 3 times.

Flow cytometry. Cells were seeded onto 6-well plates at a cell density of $2-3 \times 10^{5}$ cells/well in $2 \mathrm{ml}$ of culture medium and allowed to adhere overnight. The cells were transfected with control (NS) or plasmid DNA (pDsRed-N1 or pDsRed-BNIP3), and after $24 \mathrm{~h}$ the cells were treated with NS or L-OHP $(1 \mu \mathrm{g} / \mathrm{ml}$ in SW620 and SW620/L-OHP cells and $2.5 \mu \mathrm{g} / \mathrm{ml}$ in colo320 and colo320/L-OHP cells). Following a 48-h incubation period, the cells were harvested and apoptosis was analysed by flow cytometry using an Annexin V-fluorescein isothiocyanate/propidium iodide (FITC/PI) apoptosis detection kit (KeyGen Biotechnology Co., Ltd., Nanjing, China) according to the manufacturer's instructions. Cells were briefly harvested using trypsin-EDTA, pelleted by centrifugation, washed twice with $1 \mathrm{X}$ PBS, and resuspended in Annexin V-binding buffer. FITC-conjugated Annexin V and PI were added to the cells, incubated for $30 \mathrm{~min}$ at room temperature away from light, and then analysed by flow cytometry (ESP Elite; Beckman Coulter, Inc., Fullerton, CA, USA). Annexin V-positive cells were considered in the early stages of apoptosis, whereas cells in the late stages of apoptosis were Annexin V-and PI-positive. All experiments were conducted at least 3 times with similar results.

Hoechst 33342 staining. Cells were treated in the same way as described for flow cytometry. After 24-h incubation, the supernatant was removed and the cells were washed twice with $1 \mathrm{ml}$ chilled PBS and stained with Hoechst 33342 according to the manufacturer's instructions. Stained nuclei were visualised under fluorescence optics. The percentage of apoptotic cells, also referred to as the apoptotic ratio (AR), was calculated using the formula: AR\% = [apoptotic cells (A)/ total cell count $(\mathrm{T})]$ x 100. Approximately 10 images from each sample were acquired and analysed in 3 different experiments.

Statistical analysis. IC50 was calculated using Probit regression analysis. Results were reported as mean \pm standard deviation (SD). Results were statistically analysed using ANOVA and Student's t-test, and all analyses were conducted using the SPSS version 17.0 software (SPSS, Inc., Chicago, IL, USA). All P-values were two-sided, and $\mathrm{P}<0.05$ was considered to indicate a statistically significant difference.

\section{Results}

Recombinant BNIP3 expression. The pDsRed-N1 and pDsRed-BNIP3 plasmids were each transfected into four 

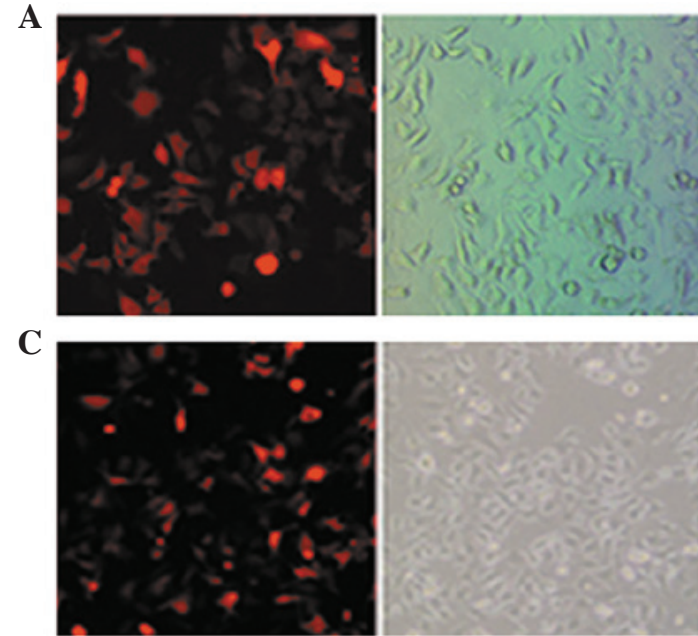

$\mathbf{E}$

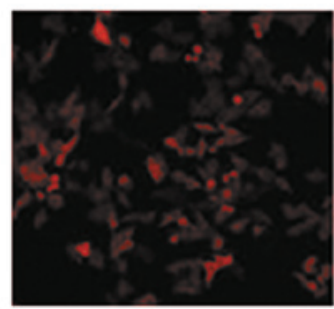

$\mathbf{G}$

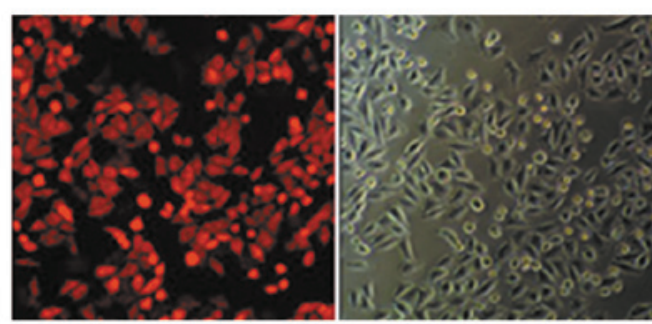

B

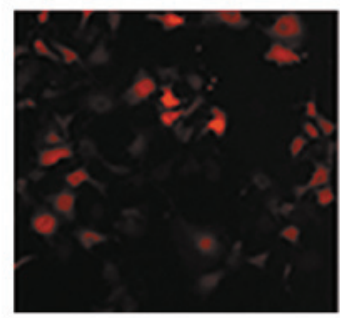

D

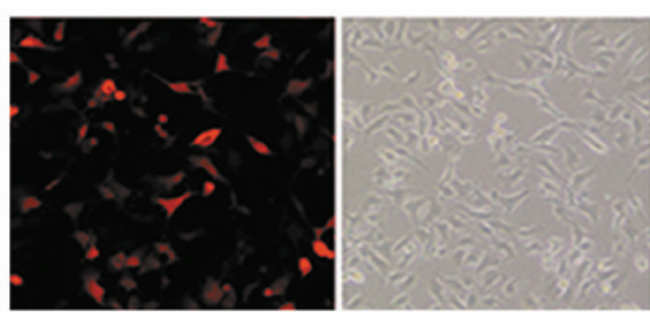

$\mathbf{F}$

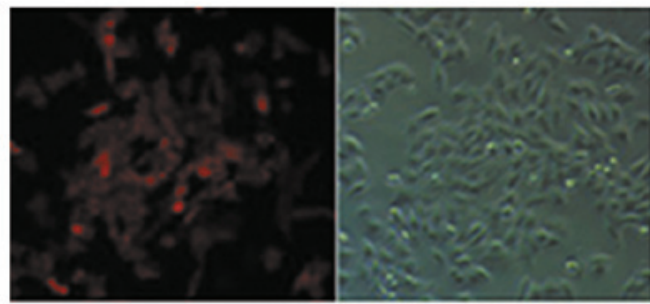

H

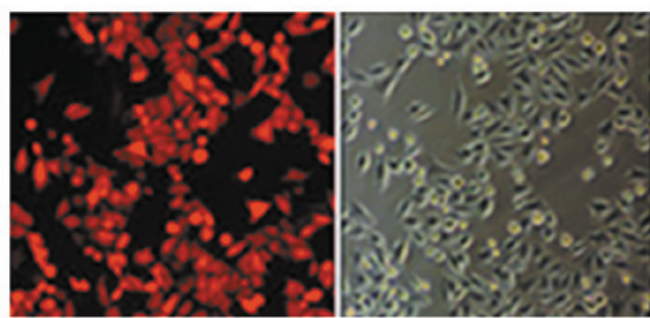

Figure 1. Fluorescein-labelled pDsRed-N1 or pDsRed-BNIP3-transfected cells were examined using fluorescence optics to determine transfection efficiency after $24 \mathrm{~h}$. The pDsRed-N1 and pDsRed-BNIP3 plasmids were transfected into the four colon cancer cell lines. The overall transfection rates were estimated to be $>60 \%$ after $24 \mathrm{~h}$ of incubation. (A) SW620-N1. (B) SW620-BNIP3. (C) SW620/L-OHP-N1. (D) DW620/L-OHP-BNIP3. (E) colo 320-N1. (F) colo320-BNIP3. (G) colo320/L-OHP-N1. (H) colo320/L-OHP-BNIP3. The images are shown in a single field of view.

colon cancer cell lines. The overall transfection rates were estimated to be $>60 \%$ following $24 \mathrm{~h}$ of incubation (Fig. 1). Recombinant plasmid expression was confirmed using western blot analysis. The results for BNIP3 revealed that cells transfected with pDsRed-BNIP3 expressed higher levels of the 60- and 30-kDa forms of the BNIP3 protein compared with the cells transfected with pDsRed-N1 and controls following a 24-h treatment (Fig. 2). Additionally, SW620/L-OHP and colo320/L-OHP cells expressed lower levels of BNIP3 protein compared with SW620 and colo320 cells, respectively (Fig. 2).

BNIP3 expression enhances the sensitivity of cells to $L-O H P$. The sensitivity of colon cancer cells to L-OHP was evaluated using the CCK 8 assay. Results revealed that at the same concentration of L-OHP, the surviving fraction of the pDsRed-BNIP3-transfected cells was significantly reduced $(\mathrm{P}<0.01)$ compared with the pDsRed-N1-transfected cells and the control groups; while that of the pDsRed-N1-transfected cells remained unchanged $(\mathrm{P}>0.05)$ compared with the control groups (Fig. 3). The surviving fraction of the pDsRed-BNIP3-transfected L-OHP-resistant cells (SW620/L-OHP-BNIP3 and colo320/L-OHP-BNIP3)
A

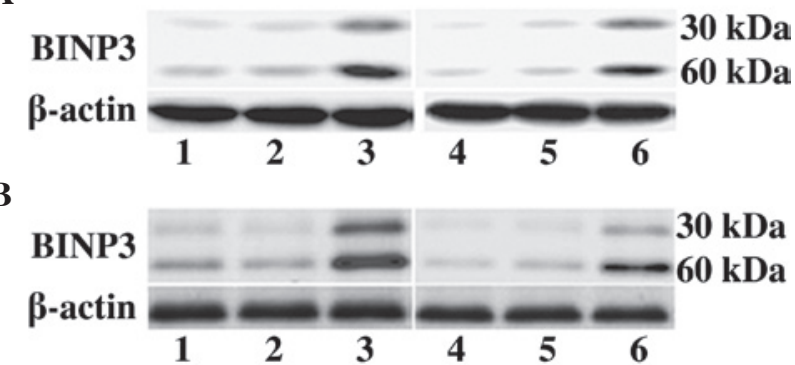

Figure 2. Western blot analysis identified BNIP3 expression in colon cancer cells after 24-h transfection. (A) Lane 1, SW620; lane 2, SW620-N1; lane 3, SW620-BNIP3; lane 4, SW620/L-OHP; lane 5, SW620/L-OHP-N1; lane 6, SW620/L-OHP-BNIP3. (B) Lane 1, colo320; lane 2, colo320-N1; lane 3, colo320-BNIP3; lane 4, colo320/L-OHP; lane 5, colo320/L-OHP-N1; lane 6 , colo320/L-OHP-BNIP3. Recombinant human BNIP3 was expressed as 2 bands of approximately 30 and $60 \mathrm{kDa}$ in pDsRed-BNIP3-transfected (lanes 3 and 6) colon cancer cells. Both forms of BNIP3 revealed a visible increase compared with the empty plasmid (pDsRed-N1)-transfected (lanes 1 and 4) or untreated (lanes 2 and 5) colon cancer cells. BNIP3 expression in the L-OHP-resistant colon cancer cell lines (SW620/L-OHP and colo320/L-OHP) was lower compared with that of the parental human colon cancer cell lines (SW620 and colo320). BNIP3, Bcl-2/adenovirus EIB 19-kDa-interacting protein 3; L-OHP, oxaliplatin. 

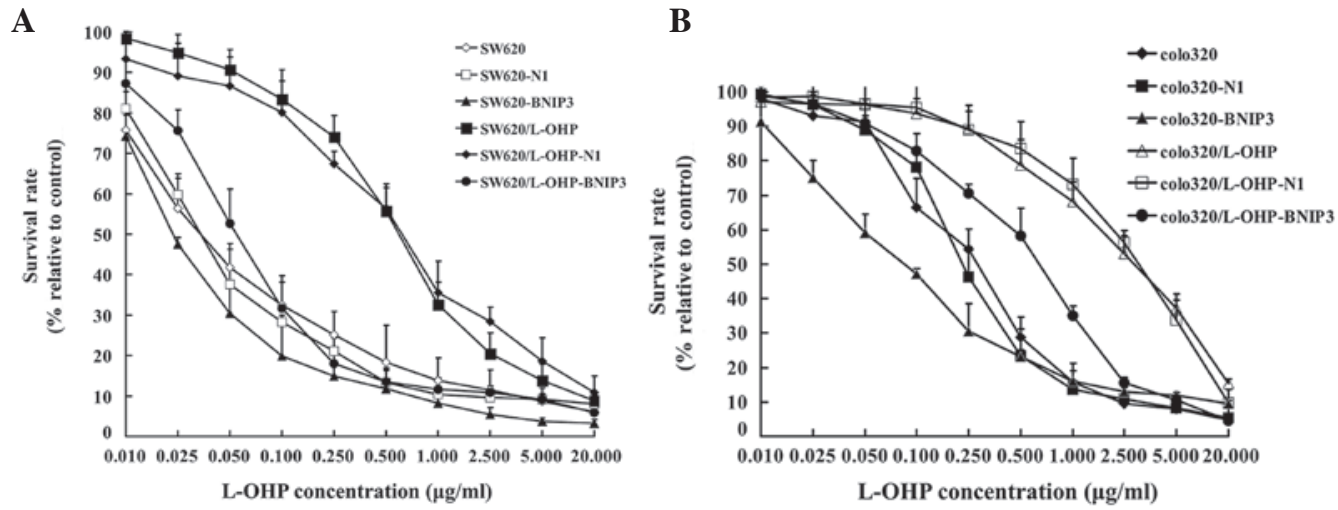

Figure 3. Survival rates of colon cancer cells treated with various concentrations of L-OHP. (A) Survival rates of SW620 and SW620/L-OHP groups. (B) Survival rates of colo320 and colo320/L-OHP groups. The CCK8 assay revealed that at the same concentration of L-OHP, the surviving fraction of the pDsRed-BNIP3-transfected cells was significantly reduced $(\mathrm{P}<0.01)$ compared with pDsRed-N1-transfected cells and the control, whereas that of the pDsRed-N1-transfected cells remained unchanged ( $\mathrm{P}>0.05)$. L-OHP, oxaliplatin; BNIP3, Bcl-2/adenovirus EIB 19-kDa-interacting protein 3. CCK8, Cell Counting Kit-8.

Table I. L-OHP sensitivities as detected by CCK8 $(\mathrm{n}=3)$.

A, SW620 and SW620/L-OHP cells

\begin{tabular}{lccc}
\hline & \multicolumn{2}{c}{$\mathrm{IC50}(\mu \mathrm{g} / \mathrm{ml})$} & \\
\cline { 2 - 3 } Group & SW620 & SW620/L-OHP & RI \\
\hline NS & $0.038 \pm 0.004$ & $0.648 \pm 0.023$ & 17.053 \\
pDsRed-N1 & $0.036 \pm 0.003$ & $0.647 \pm 0.028$ & 17.972 \\
pDsRed-BNIP3 & $0.020 \pm 0.002^{\mathrm{a}}$ & $0.067 \pm 0.005^{\mathrm{b}}$ & 3.35 \\
\hline
\end{tabular}

B, Colo320 and colo320/L-OHP cells

\begin{tabular}{lccc}
\hline & \multicolumn{2}{c}{$\mathrm{IC50}(\mu \mathrm{g} / \mathrm{ml})$} & \\
\cline { 2 - 3 } Group & Colo320 & Colo320/L-OHP & \multirow{2}{*}{ RI } \\
\hline NS & $0.294 \pm 0.014$ & $2.668 \pm 0.333$ & 9.075 \\
pDsRed-N1 & $0.295 \pm 0.020$ & $2.631 \pm 0.267$ & 8.919 \\
pDsRed-BNIP3 & $0.114 \pm 0.009^{\mathrm{b}}$ & $0.601 \pm 0.005^{\mathrm{b}}$ & 5.272 \\
\hline
\end{tabular}

Values are shown as mean $\pm \mathrm{SD}$. Results revealed that the sensitivity of cells transfected with pDsRed-BNIP3 to L-OHP was lower $\left({ }^{\mathrm{a}} \mathrm{P}<0.05\right.$, $\left.{ }^{\mathrm{b}} \mathrm{P}<0.01\right)$ compared with that of the control and pDsRed-N1-transfected groups. L-OHP, oxaliplatin, CCK8, Cell Counting Kit-8; IC50, concentration of L-OHP that caused a $50 \%$ reduction in the number of cells; RI, resistance index.

did not significantly differ $(\mathrm{P}>0.05)$ from that of the pDsRed-BNIP3-transfected parental cells (SW620-BNIP3 and colo320-BNIP3). As shown in Table I, the IC50 values of the pDsRed-BNIP3-transfected cells were significantly reduced $(\mathrm{P}<0.01)$ compared with those of the pDsRed-N1-transfected cells and the control groups. By contrast, the pDsRed-BNIP3-transfected L-OHP-resistant cells (SW620/L-OHP-BNIP3 and colo320/L-OHP-BNIP3) did not significantly differ in this regard $(\mathrm{P}>0.05)$ from the pDsRed-BNIP3-transfected parental cells (SW620-BNIP3 and colo320-BNIP3). BNIP3 was revealed to reverse the drug resistance of SW620/L-OHP and colo320/L-OHP to L-OHP
Table II. Apoptosis rates detected by Annexin V-FITC/PI ( $n=3)$.

A, SW620 and SW620/L-OHP cells

\begin{tabular}{lcc}
\hline Group & $\begin{array}{c}\text { L-OHP } \\
(0 \mu \mathrm{g} / \mathrm{ml})\end{array}$ & $\begin{array}{c}\text { L-OHP } \\
(1 \mu \mathrm{g} / \mathrm{ml})\end{array}$ \\
\hline SW620 & $4.28 \pm 0.47$ & $33.43 \pm 2.68$ \\
SW620-N1 & $6.12 \pm 1.03$ & $35.8 \pm 4.6$ \\
SW620-BNIP3 & $24.30 \pm 3.61^{\mathrm{a}}$ & $53.50 \pm 2.86^{\mathrm{b}}$ \\
SW620/L-OHP & $4.15 \pm 0.39$ & $20.74 \pm 3.11$ \\
SW620/L-OHP-N1 & $6.32 \pm 1.08$ & $21.06 \pm 2.62$ \\
SW620/L-OHP-BNIP3 & $17.34 \pm 0.39^{\mathrm{a}}$ & $47.93 \pm 4.82^{\mathrm{b}}$ \\
\hline
\end{tabular}

B, Colo320 and colo320/L-OHP cells

\begin{tabular}{lcc}
\hline Group & $\begin{array}{c}\text { L-OHP } \\
(0 \mu \mathrm{g} / \mathrm{ml})\end{array}$ & $\begin{array}{c}\text { L-OHP } \\
(2.5 \mu \mathrm{g} / \mathrm{ml})\end{array}$ \\
\hline Colo320 & $4.44 \pm 0.63$ & $33.22 \pm 0.85$ \\
Colo320-N1 & $6.68 \pm 0.88$ & $34.40 \pm 0.72$ \\
Colo320-BNIP3 & $17.81 \pm 2.47^{\mathrm{a}}$ & $51.98 \pm 1.84^{\mathrm{b}}$ \\
Colo320/L-OHP & $4.11 \pm 1.02$ & $20.53 \pm 2.36$ \\
Colo320/L-OHP-N1 & $6.09 \pm 1.85$ & $22.24 \pm 1.20$ \\
Colo320/L-OHP-BNIP3 & $16.59 \pm 2.35^{\mathrm{a}}$ & $49.79 \pm 1.13^{\mathrm{b}}$ \\
\hline
\end{tabular}

Values are shown as mean $\pm \mathrm{SD}$. The pDsRed-BNIP3-transfected cells exhibited higher $\left({ }^{\mathrm{a}} \mathrm{P}<0.05\right)$ apoptosis rates compared with those of the pDsRed-N1-transfected cells and control groups. Compared with the untransfected cells treated with L-OHP and pDsRed-BNIP3transfected cells, the apoptosis regulator in combination with L-OHP significantly increased the apoptosis rates $\left({ }^{\mathrm{b}} \mathrm{P}<0.01\right)$ in parental and L-OHP-resistant colon cancer cell lines. FITC, fluorescein isothiocyanate; PI, propidium iodide; L-OHP, oxaliplatin; BNIP3, Bcl-2/ adenovirus EIB 19-kDa-interacting protein 3.

by 9.67 and 4.44 times, respectively. These results indicate that the BNIP3 protein not only enhanced the sensitivity of parental colon cancer cells, but also reversed drug resistance in L-OHP-resistant colon cancer cells. 
A
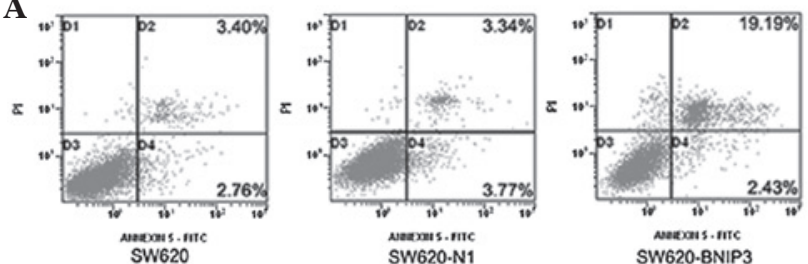

SW620-BNIP3

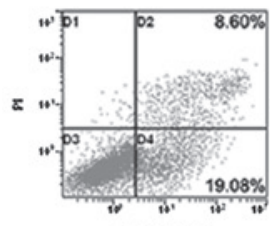

SW620+L.OHP

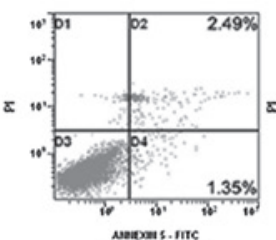

SW620/L-OHP

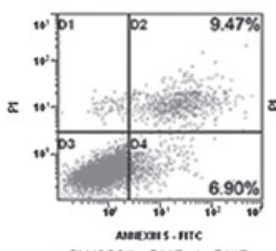

SW620/.OHP+L.OHP

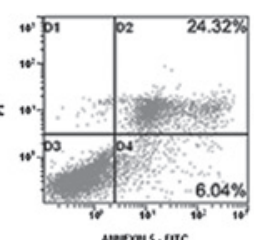

SW620-N1+L-OHP

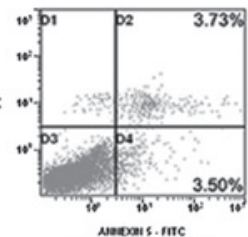

SW620/-OHP.N1

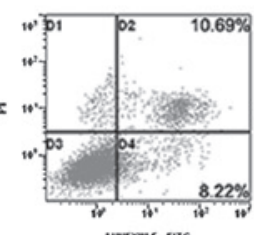

SW620/.OHP.N1+L.OHP

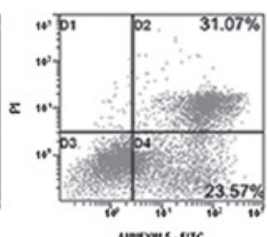

SW620-BNIP3+L-OHP

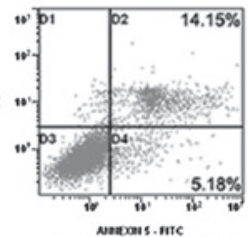

SW620/L-OHP-8NIP3

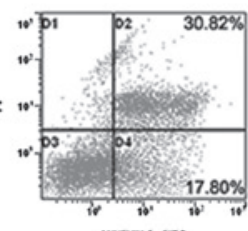

SW620R.OHP.BNIP3+L-OHP
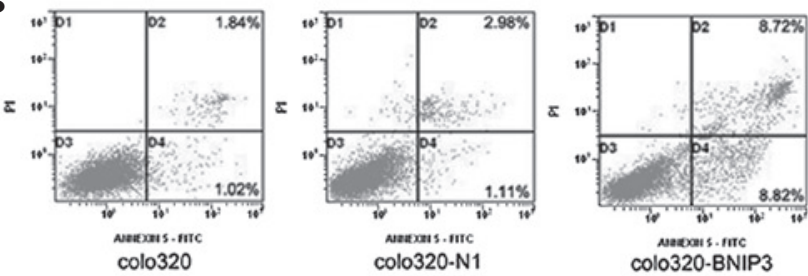

colo320-BNIP3
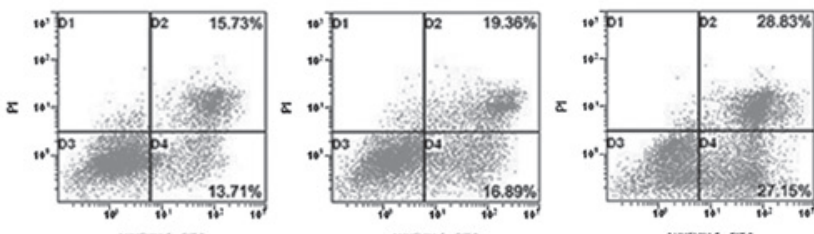

Colo320-N1+L-OHP
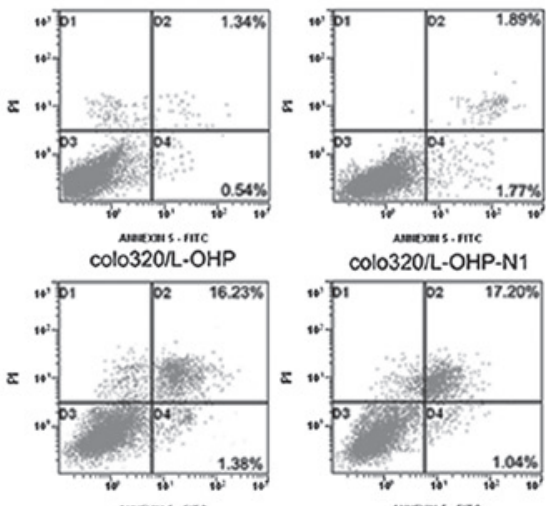

colo320/.OHP+L-OHP

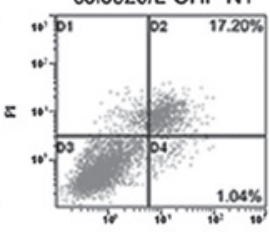

colo320/L-OHP-N1+L-OHP colo320/L-OHP-BNIP3+L-OHP

Figure 4. Apoptosis of colon cancer cells as detected by Annexin V-FITC/PI. Quadrant 1, PI(+) (cells undergoing necrosis); Quadrant 2, Annexin V-FITC(+) PI(+) (cells in the late period of apoptosis and undergoing secondary necrosis); Quadrant 3, Annexin V-FITC(-) PI(-) (living cells); Quadrant 4, Annexin V-FITC(+) PI(-) (cells in the early period of apoptosis). The total AR was calculated as Quadrant $2+$ Quadrant 4. The pDsRed-BNIP3-transfected cells exhibited higher apoptotic rates compared with the pDsRed-N1-transfected cells and the control. Compared with the untransfected cells treated with L-OHP and the pDsRed-BNIP3-transfected cells, the apoptosis regulator in combination with L-OHP significantly increased the apoptosis rates in parental and L-OHP-resistant colon cancer cell lines. FITC, fluorescein isothiocyanate; PI, propidium iodide; BNIP3, Bcl-2/adenovirus EIB 19-kDa-interacting protein 3; L-OHP, oxaliplatin; AR, apoptosis rate.

BNIP3 expression enhances L-OHP-induced apoptosis. Cell apoptosis was detected using Annexin V-FITC/PI. Fig. 4 and Table II show that the pDsRed-BNIP3-transfected cells exhibited significantly higher $(\mathrm{P}<0.01)$ apoptosis rates compared with the pDsRed-N1-transfected cells and control groups. Compared with the untransfected cells treated with L-OHP and pDsRed-BNIP3-transfected cells, BNIP3 in combination with L-OHP resulted in significantly higher rates of apoptosis $(\mathrm{P}<0.01)$ in the parental and L-OHP-resistant colon cancer cell lines. By contrast, the rates of apoptosis of the pDsRed-BNIP3-transfected L-OHP-resistant cells (SW620/L-OHP-BNIP3 and colo320/L-OHP-BNIP3) did not significantly differ $(\mathrm{P}>0.05)$ from those of the pDsRed-BNIP3transfected parental cells (SW620-BNIP3 and colo320-BNIP3). These results indicate that the expression of the BNIP3 protein not only exerted a proapoptotic effect on colon cancer cells but also conferred chemosensitivity on drug-resistant colon cancer cells. Additionally, the results indicate that the expression of BNIP3 combined with L-OHP resulted in a higher apoptosis index relative to that of cells treated with $B N I P 3$ or L-OHP alone.

Cell apoptosis as detected by Hoechst 33342 staining. The effects of BNIP3 expression on the chemosensitivity of colon cancer cells were verified further by Hoechst 33342 staining. Once the cells were stained with Hoechst 33342, typical morphological findings of apoptosis, including chromatin condensation and apoptotic bodies, were visualised under fluorescence optics (Fig. 5A and B). The percentage of apoptotic cells (AR\%) was calculated as previously described, and the results were confirmed using flow cytometry. The expression of BNIP3 not only exerted a proapoptotic effect on colon cancer cells but also conferred chemosensitivity on drug-resistant colon cancer cells. Additionally, the results indicate that expression of BNIP3 combined with L-OHP resulted in a higher apoptosis index relative to that of the cells treated with BNIP3 or L-OHP alone (Fig. 5C and D).

\section{Discussion}

Drug resistance remains a significant obstacle for successful chemotherapy in colon cancer. Mechanisms of resistance to platinum agents, such as L-OHP, include increased DNA repair, overexpression of copper transporters, enhanced drug detoxification and increased tolerance for DNA damage $(15,16)$. However, despite the fact that the mechanisms influencing treatment responses are well known, it appears that the major process leading to chemotherapy 
A

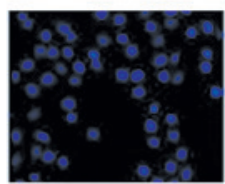

SW620

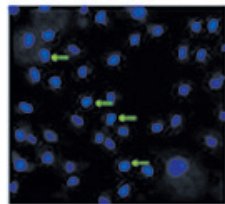

SW620+L-OHP

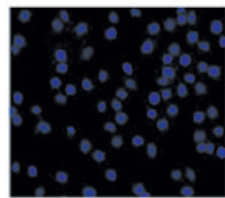

SW620/L.OHP

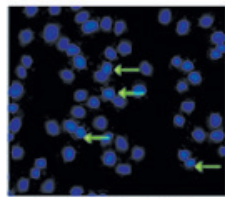

SW620/L-OHP $+L \cdot O H P$

C

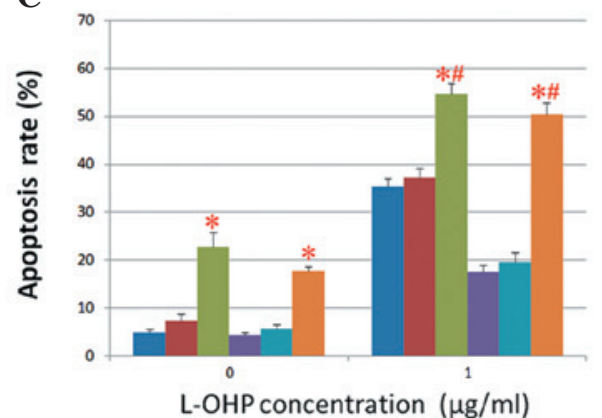

SW620-N1

SW620-N1+L-OHP

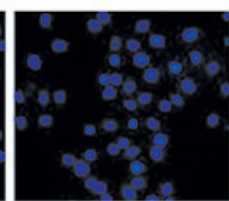

SW620/L.OHP.N1

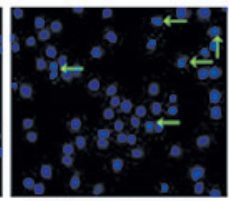

B
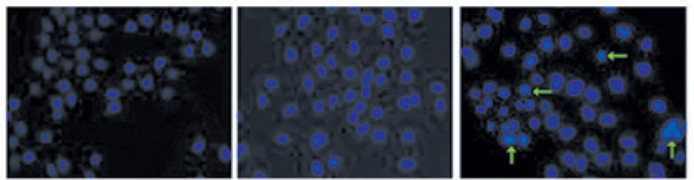

SW620-BNIP3
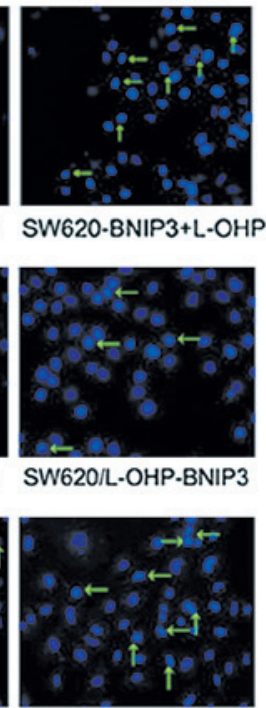

SW620/L-OHP-BNIP1 $+\mathrm{L} \cdot \mathrm{OHP}$

W620/2.OHP.N + L.OHP

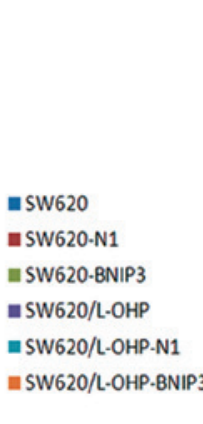

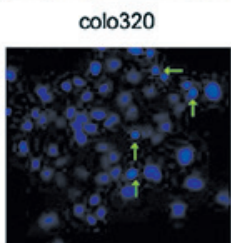

colo320-N1

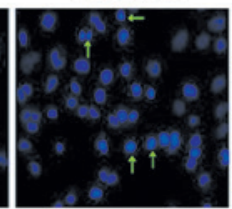

colo320-BNIP3

colo320+L-OHP

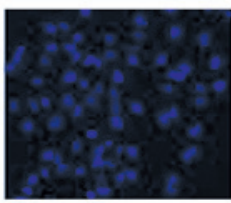

colo320/L-OHP

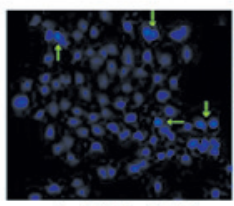

colo320/L-OHP

+ L-OHP
colo320-N1+L-OHP

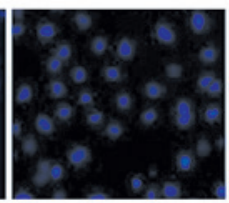

colo320/L-OHP-N1

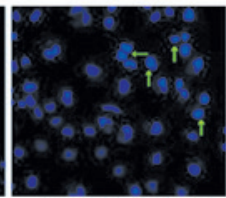

colo320/L-OHP-N1 colo320/L-OHP-BNIP3

$+\mathrm{L}-\mathrm{OHP} \quad+\mathrm{L}-\mathrm{OHP}$

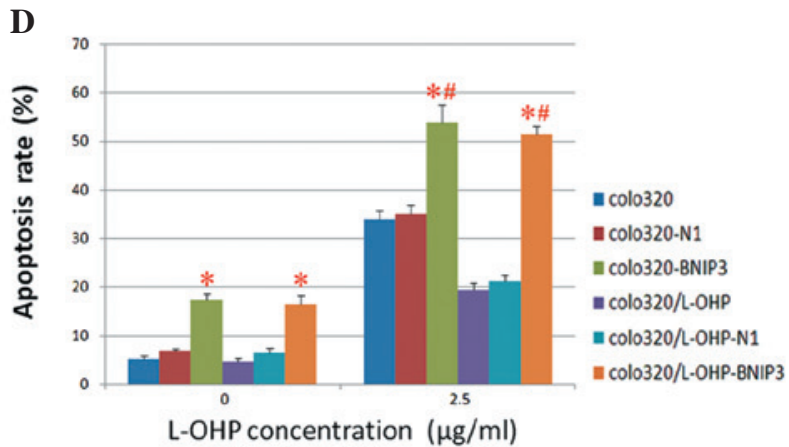

Figure 5. (A and B) Morphological features of colon cancer cells undergoing apoptosis, as observed under the fluorescence optics using Hoechst 33342 staining. Typical morphological features of apoptosis, including chromatin condensation and apoptotic bodies, were visualised in pDsRed-BNIP3-transfected cells, compared with the pDsRed-N1-transfected cells and control groups. (C and D) AR of colon cancer cells as detected by Hoechst 33342 staining. pDsRed-BNIP3-transfected cells exhibited higher $\left({ }^{*} \mathrm{P}<0.01\right)$ apoptotic rates than the pDsRed-N1-transfected cells and control groups. Compared with the untransfected cells treated with L-OHP and pDsRed-BNIP3-transfected cells, the apoptosis regulator in combination with L-OHP significantly increased the apoptotic rates $(" \mathrm{P}<0.01)$ in parental and L-OHP-resistant colon cancer cell lines. L-OHP, oxaliplatin; AR, apoptosis rate.

resistance are associated with the lack or inhibition of proapoptotic regulators (17-19).

Apoptosis is the predominant mechanism of cell death induced by chemotherapy and radiation treatments (20). Regulation of apoptosis is a delicate and complex process, and two major genes (p53 and Bcl-2) have been identified to be involved in this process. As one of the downstream genes of $\mathrm{p} 53$, the gene encoding the proapoptotic BNIP3 protein should participate in the apoptotic process following chemotherapy and radiotherapy (21) during which BNIP3 forms heterodimers and interacts with antiapoptotic molecules, including Bcl-2 or Bcl-xl. The heterodimer form of BNIP3 prompts activated Bax and Bak to adhere to the outer mitochondrial membrane, forming a tetramer channel, which in turn induces the mitochondria to release cytochrome $\mathrm{c}$ and activate caspase-9-dependent apoptosis (22). As a mitochon- drial protein, BNIP3 induces apoptosis when transiently overexpressed, opening the mitochondrial permeability transition pore (MPTP) and releasing cytochrome $\mathrm{c}$ from the mitochondrial intermembranous space into the cytoplasm, subsequently promoting apoptosis (5,23-27). However, we observed that BNIP3 expression was reduced in most tumour tissues compared with healthy tissues, yet similar to pancreatic, haematopoietic and gastric cancers (6-8).

Our previous study revealed that BNIP3 may play a role in the enhancement of radiotherapy efficiency (9). Tumour chemoresistance correlates with abnormal expression of BNIP3, and previous studies have revealed that the downregulation of BNIP3 increased resistance to 5-FU and gemcitabine in pancreatic cancer cells $(10,11)$. Loss of BNIP3 expression, which occurs late in pancreatic cancer, contributes to chemotherapy resistance and correlates with poor prognosis $(10,11)$. 
Murai et al (7) revealed that the expression of BNIP3 was reduced in colon cancer cell lines that were chemoresistant to 5-FU. Tang et al (12) identified that colon cancer cell lines resistant to L-OHP expressed low levels of BNIP3, and were also resistant to 5-FU. Other studies reached similar conclusions, indicating that BNIP3 expression correlates with chemoresistance $(11,13,14)$. Whether the expression of BNIP3 correlates with the reversal of drug resistance in tumour cells remains unknown.

To determine the potential of BNIP3 as a therapeutic target for chemosensitisation, we overexpressed BNIP3 in parental and L-OHP-resistant colon cancer cell lines by transfection with pDsRed-BNIP3 in vitro. The results revealed that the L-OHP-resistant colon cancer cells expressed lower levels of BNIP3 compared with the parental cells. As confirmed by fluorescence microscopy and western blot analysis, BNIP3 expression was successfully increased in parental and L-OHP-resistant colon cancer cells using the pDsRed-BNIP3 treatment strategy. Furthermore, CCK8 demonstrated that the overexpression of BNIP3 could not only enhance the sensitivity of parental colon cancer cells but also reverse the drug resistance of L-OHP-resistant colon cancer cells Subsequently, we identified the presence of apoptotic cells using flow cytometry and Hoechst 33342 staining, indicating that BNIP3 overexpression not only exerts a proapoptotic effect on colon cancer cells but also confers chemosensitivity on drug-resistant colon cancer cells. Additionally, the results revealed that the expression of BNIP3 combined with L-OHP resulted in a higher apoptosis index relative to the apoptosis index of cells treated with BNIP3 or L-OHP alone.

The exact mechanism by which BNIP3 overexpression reverses the resistance of drug-resistant cancer cells and increases drug-induced apoptosis has not been fully elucidated. BNIP3 is a downstream gene of p53, with a probable chemosensitisation mechanism involving BNIP3. Firstly, the overexpression of BNIP3 enhances the proapoptotic activity via the intrinsic apoptotic pathways. The heterodimer form of BNIP3 prompts the activated Bax and Bak to adhere and consequently open MPTP, releasing cytochrome $\mathrm{c}$ from the mitochondrial intermembranous space into the cytoplasm, and ultimately promoting apoptosis (5,23-27). Secondly, BNIP3 inhibits the effects of antiapoptotic molecules. BNIP3 forms heterodimers and interacts with antiapoptotic molecules, including $\mathrm{Bcl}-2$ or $\mathrm{Bcl}-\mathrm{xl}$, and suppresses the antiapoptotic effects. Bcl-2, originally identified as a universal inhibitor of apoptotic cell death, has since been implicated in suppressing autophagy, functioning as a promoter of oncogenic growth, synergistically promoting tumour growth and promoting cancer development and drug resistance (28). As a Bcl-2 family member with similar antiapoptotic features to Bcl-2, Bcl-xl displayed the same pattern of combinatorial interactions with Bcl-2 family proteins. The suppression of Bcl-xl, which is involved in the process of drug resistance, could improve chemotherapy efficacy in colon tumours (29). Lastly, BNIP3 interacts with other drug resistance-related molecules, including P-gp, MRP, MDR and LRP. Additionally, BNIP3 facilitates mitochondrial autophagy (30).

In conclusion, BNIP3 expression not only enhances the sensitivity of parental colon cancer cells but also reverses the resistance of L-OHP-resistant colon cancer cells. Furthermore, the combined treatment with BNIP3 and L-OHP exerted a synergistic effect on apoptosis rates in L-OHP-resistant colon cancer cells. However, the exact mechanism by which BNIP3 expression reversed the resistance of drug-resistant cancer cells and increased drug-induced apoptosis requires further study. Subsequent clinical trials aimed at evaluating the chemosensitisation effect of BNIP3 expression on colon cancer are required.

\section{References}

1. Jemal A, Bray F, Center MM, Ferlay J, Ward E and Forman D: Global cancer statistics. CA Cancer J Clin 61: 69-90, 2011.

2. Segal NH and Saltz LB: Evolving treatment of advanced colon cancer. Annu Rev Med 60: 207-219, 2009.

3. Tournigand C, André T, Achille E, Lledo G, Flesh M, Mery-Mignard D, Quinaux E, Couteau C, Buyse M, Ganem G, Landi B, Colin P, Louvet C and de Gramont A: FOLFIRI followed by FOLFOX6 or the reverse sequence in advanced colorectal cancer: a randomized GERCOR study. J Clin Oncol 22: 229-237, 2004

4. Wu DL, Huang F and Lu HZ: Drug-resistant proteins in breast cancer: recent progress in multidrug resistance. Chin J Cancer 22: 441-444, 2003

5. Vande Velde C, Cizeau J, Dubik D, Alimonti J, Brown T, Israels S, Hakem R and Greenberg AH: BNIP3 and genetic control of necrosis-like cell death through the mitochondrial permeability transition pore. Mol Cell Biol 20: 5454-5468, 2000.

6. Murai M, Toyota M, Suzuki H, Satoh A, Sasaki Y, Akino K, Ueno M, Takahashi F, Kusano M, Mita H, Yanagihara K, Endo T, Hinoda Y, Tokino T and Imai K: Aberrant methylation and silencing of the BNIP3 gene in colorectal and gastric cancer. Clin Cancer Res 11: 1021-1027, 2005.

7. Murai M, Toyota M, Satoh A, Suzuki H, Akino K, Mita H, Sasaki Y, Ishida T, Shen L, Garcia-Manero G, Issa JP, Hinoda Y, Tokino T and Imai K: Aberrant DNA methylation associated with silencing BNIP3 gene expression in haematopoietic tumours. $\mathrm{Br}$ J Cancer 92: 1165-1172, 2005.

8. Okami J, Simeone DM and Logsdon CD: Silencing of the hypoxia-inducible cell death protein BNIP3 in pancreatic cancer. Cancer Res 64: 5338-5346, 2004.

9. Wang Z, Huang CM, Deng Q, Zeng H, Wang X, Zhang S, Bi F, Tang QL, Zhong RM, Li AJ, He YB, Chen N, Li ZP and Wang W: Effects of the proapoptotic regulator Bcl2/adenovirus EIB $19 \mathrm{kDa}$-interacting protein 3 on radiosensitivity of cervical cancer. Cancer Biother Radiopharm 26: 279-286, 2011.

10. Akada M, Crnogorac-Jurcevic T, Lattimore S, Mahon P, Lopes R, Sunamura M, Matsuno S and Lemoine NR: Intrinsic chemoresistance to gemcitabine is associated with decreased expression of BNIP3 in pancreatic cancer. Clin Cancer Res 11: 3094-3101, 2005.

11. Erkan M, Kleeff J, Esposito I, Giese T, Ketterer K, Büchler MW, Giese NA and Friess H: Loss of BNIP3 expression is a late event in pancreatic cancer contributing to chemoresistance and worsened prognosis. Oncogene 24: 4421-4432, 2005.

12. Tang H, Liu YJ, Liu M and Li X: Establishment and gene analysis of an oxaliplatin-resistant colon cancer cell line THC8307/L-OHP. Anticancer Drugs 18: 633-639, 2007.

13. Valdez BC, Murray D, Ramdas L, de Lima M, Jones R, Kornblau S, Betancourt D, Li Y, Champlin RE and Andersson BS: Altered gene expression in busulfan-resistant human myeloid leukemia. Leukemia Research 32: 1684-1697, 2008.

14. Ishiguro M, Iida S, Uetake H, Morita S, Makino H, Kato K, Takagi Y, Enomoto M and Sugihara K: Effect of combined therapy with low-dose 5-Aza-2'-deoxycytidine and irinotecan on colon cancer cell line HCT-15. Ann Surg Oncol 14: 1752-1762, 2007.

15. Desoize B and Madoulet C: Particular aspects of platinum compounds used at present in cancer treatment. Crit Rev Oncol Hematol 42: 317-325, 2002.

16. Chen CC, Chen LT, Tsou TC, Pan WY, Kuo CC, Liu JF, Yeh SC, Tsai FY, Hsieh HP and Chang JY: Combined modalities of resistance in an oxaliplatin-resistant human gastric cancer cell line with enhanced sensitivity to 5-fluorouracil. Br J Cancer 97: 334-344, 2005.

17. Mitsiades N, Yu WH, Poulaki V, Tsokos M and Stamenkovic I: Matrix metalloproteinase-7-mediated cleavage of Fas ligand protects tumor cells from chemotherapeutic drug cytotoxicity. Cancer Res 61: 577-581, 2001. 
18. Assaraf YG, Rothem L, Hooijberg JH, Stark M, Ifergan I, Kathmann I, Dijkmans BA, Peters GJ and Jansen G: Loss of multidrug resistance protein 1 expression and folate efflux activity results in a highly concentrative folate transport in human leukemia cells. J Biol Chem 278: 6680-6686, 2003.

19. Peter ME, Legembre P and Barnhart BC: Does CD95 have tumor promoting activities? Biochim Biophys Acta 1755: 25-36, 2005.

20. Fulda S and Debatin KM: Extrinsic versus intrinsic apoptosis pathways in anticancer chemotherapy. Oncogene 25: 4798-4811, 2006.

21. Fei P, Wang W, Kim SH, Wang S, Burns TF, Sax JK, Buzzai M, Dicker DT, McKenna WG, Bernhard EJ and El-Deiry WS: Bnip3L is induced by p53 under hypoxia, and its knockdown promotes tumor growth. Cancer Cell 6: 597-609, 2004.

22. van Loo G, Saelens X, van Gurp M, MacFarlane M, Martin SJ and Vandenabeele P: The role of mitochondrial factors in apoptosis: a Russian roulette with more than one bullet. Cell Death Differ 9: 1031-1042, 2002.

23. Susin SA, Lorenzo HK, Zamzami N, Marzo I, Snow BE, Brothers GM, Mangion J, Jacotot E, Costantini P, Loeffler M, Larochette N, Goodlett DR, Aebersold R, Siderovski DP, Penninger JM and Kroemer G: Molecular characterization of mitochondrial apoptosis-inducing factor. Nature 397: 441-446, 1999.
24. Kim JY, Cho JJ, Ha J and Park JH: The carboxy terminal C-tail of BNip3 is crucial in induction of mitochondrial permeability transition in isolated mitochondria. Arch Biochem Biophys 398: 147-152, 2002.

25. Love S: Apoptosis and brain ischemia. Prog Neuropsychophermacol Biol Psychiatry 27: 267-282, 2003

26. Burlacu A: Regulation of apoptosis by $\mathrm{Bcl}-2$ family protein J Cell Mol Med 7: 249-257, 2003.

27. Reed JC: Mechanisms of apoptosis. Am J Pathol 157: 1415-1430, 2000.

28. Oh S, Pirooz SD, Ni D, Zhao Z and Liang C: Anti-autophagic Bcl-2: not just an innocent bystander. Autophagy 7: 231-232, 2011.

29. D'Anselmi F, Cucina A, Biava PM, Proiettir S, Coluccia P, Frati L and Bizzarri M: Zebrafish stem cell differentiation stage factors suppress $\mathrm{Bcl}-\mathrm{xL}$ release and enhance 5-Fu-mediated apoptosis in colon cancer cells. Curr Pharm Biotechnol 12: 261-267, 2011.

30. Zhang H, Bosch-Marce M, Shimoda LA, Tan YS, Baek JH, Wesley JB, Gonzalez FJ and Semenza GL: Mitochondrial autophagy is an HIF-1-dependent adaptive metabolic response to hypoxia. J Biol Chem 283: 10892-10903, 2008. 